\title{
Estimating cloud optical thickness and associated surface UV irradiance from SEVIRI by implementing a semi-analytical cloud retrieval algorithm
}

\author{
P. Pandey ${ }^{1,2}$, K. De Ridder ${ }^{1}$, D. Gillotay ${ }^{3}$, and N. P. M. van Lipzig ${ }^{2}$ \\ ${ }^{1}$ VITO - Flemish Institute for Technological Research, Mol, Belgium \\ ${ }^{2}$ Department of Earth- and Environmental Sciences, K. U. Leuven, Leuven, Belgium \\ ${ }^{3}$ Belgian Institute for Space Aeronomy, Brussels, Belgium \\ Correspondence to: P. Pandey (praveen.pandey@vito.be and praveenkumarpandey@gmail.com) \\ Received: 6 November 2011 - Published in Atmos. Chem. Phys. Discuss.: 9 January 2012 \\ Revised: 14 August 2012 - Accepted: 21 August 2012 - Published: 6 September 2012
}

\begin{abstract}
In this paper, we describe the implementation of the Semi-Analytical Cloud Retrieval Algorithm (SACURA), to obtain scaled cloud optical thickness (SCOT) from satellite imagery acquired with the SEVIRI instrument and surface UV irradiance levels. In estimation of SCOT particular care is given to the proper specification of the background (i.e. cloud-free) spectral albedo and the retrieval of the cloud water phase from reflectance ratios in SEVIRI's $0.6 \mu \mathrm{m}$ and $1.6 \mu \mathrm{m}$ spectral bands. The SACURA scheme is then applied to daytime SEVIRI imagery over Europe, for the month of June 2006, at 15-min time increments. The resulting SCOT fields are compared with values obtained by the CloudSat experimental satellite mission, yielding a negligible bias, correlation coefficients ranging from 0.51 to 0.78 , and a root mean square difference of 1 to 2 SCOT increments. These findings compare favourably to results from similar intercomparison exercises reported in the literature. Based on the retrieved SCOT from SEVIRI and radiative transfer modelling approach, simple parameterisations are proposed to estimate the surface UV-A and UV-B irradiance. The validation of the modelled UV-A and UV-B irradiance against the measurements over two Belgian stations, Redu and Ostend, indicate good agreement with the high correlation, index of agreement and low bias. The SCOT fields estimated by implementing SACURA on imagery from geostationary satellite are reliable and its impact on surface UV irradiance levels is well produced.
\end{abstract}

\section{Introduction}

Clouds play an important role in the Earth's climate system. In addition to Earth's hydrological cycle (Lin et al., 2000), cloud properties are also crucial to global climate studies (Nakajima and King, 1990). In particular, clouds modulate solar radiation intensity in the Earth-atmosphere system (Kidder and Vonder Haar, 1995) and play an important role in variation of UV irradiance at the surface of the Earth (Lubin and Jensen, 1995; Moreno et al., 2003). The UV radiation, in particular UV-A and UV-B radiations, reaching the Earth's surface (Kudish and Evseev, 2000), act efficiently in driving the atmospheric chemistry at the surface by affecting different photolysis reactions (Madronich, 1987; Monks et al., 2004). Thus, the cloud fields significantly affect the radiative fluxes, thereafter the photochemistry and hence the air quality at the surface of the Earth.

The high temporal and spatial variation of clouds poses a challenge in determination of radiative fluxes, which includes the UV part of the solar spectrum, and the photochemical processes associated with them at the Earth's surface together with the health effects (Calbó et al., 2005; Vázquez and Hanslmeier, 2006). The effect of cloud on UV irradiance has been studied in the past by means of observations and modelling (Alados-Arboledas et al., 2003; Estupinan et al., 1996; Mateos et al., 2011; Moreno et al., 2003; Seckmeyer et al., 1996). These studies largely focus on UV erythemal irradiance and cloud modification factor, which is defined as the ratio of UV irradiance under cloudy condition to clear sky UV irradiance. It has been reported that in general clouds re-

Published by Copernicus Publications on behalf of the European Geosciences Union. 
duce the UV radiation reaching the Earth's surface, but under certain conditions clouds can enhance the surface UV radiation compared to clear sky condition (Crawford et al., 2003; Sabburg and Parisi, 2006). In general, these studies reveal the diverse influence of cloud. Therefore, to obtain a good estimate of surface solar/UV irradiance for air quality research, better description of cloud properties is a prerequisite.

Cloud abundance, and more specifically the effect of cloud on radiative transfer, is commonly expressed quantitatively by means of the cloud optical thickness (COT, see e.g. Kokhanovsky, 2006). Several methods (see e.g. Nakajima et al., 1990; King et al., 1992) are available to estimate the physical properties of clouds, such as cloud optical thickness and droplet effective radius, from remote sensing imagery. They are based on clouds' spectral absorption and reflection properties in the shortwave radiation spectrum. These methods generally use a look up table (LUT) approach, which is based on storing results of detailed atmospheric radiative transfer calculations, for a pre-defined set of atmospheric and viewing conditions. Recently Roebeling et al. (2006) applied an LUT-based approach to imagery from a geostationary platform for climate monitoring.

As an alternative and very fast approach, Kokhanovsky et al. (2003) developed a semi-analytical cloud retrieval algorithm (SACURA). Nauss et al. (2005) compared LUT based approaches with SACURA using Moderate Resolution Imaging Spectroradiometer (MODIS) data. Kokhanovsky and Nauss (2005) applied SACURA to derive ice cloud properties from Hurricane Jeanne using MODIS. An intercomparison of cloud optical thickness from the Scanning Imaging Absorption Spectrometer for Atmospheric Cartography (SCIAMACHY), Medium Resolution Imaging Spectrometer (MERIS) and Advanced Along Track Scanning Radiometer (AATSR) is shown by Kokhanovsky et al. (2007).

Applications of the SACURA method have been limited to imagery from polar satellite platforms, which have a rather poor sampling frequency as compared to the time scales of the evolution of cloud decks. In many domains, a continuous cloud property monitoring is essential; therefore, we propose to apply SACURA on imagery from a geostationary platform. In particular, use will be made of imagery generated by the Spinning Enhanced Visible and Infra Red Imager (SEVIRI) onboard the Meteosat Second Generation (MSG) satellite platform. The SACURA-derived COT from MSG is compared with a totally independent estimation of COT from CloudSat instrument. Subsequently, as the study presented here is in fact carried out in the context of a better estimate of photolysis rate coefficients required in the chemistry schemes of atmospheric pollution models, develop a simple parameterisation to relate remotely sensed COT to surface UV irradiance. The parameterisation is developed with the purpose to verify the capacity of retrieved COT to yield reasonable surface UV irradiance. Finally, the calculated surface UV irradiance is validated with two UV monitoring stations in Belgium.
The remainder of this paper is organised as follows. Section 2 details the data and methodology to retrieve COT and then to estimate the surface UV irradiance levels associated with the COT. The comparison between retrieved COT values with the COT values from the dedicated CloudSat instrument is shown in Sect. 3. In addition to this, the validation of the estimated surface UV irradiance against station-based measurements in Belgium is also illustrated in Sect. 3. We summarise our findings in Sect. 4.

\section{Data and methodology}

The data and methodology used to retrieve cloud optical thickness $(\tau)$ and surface UV irradiance associated with the $\tau$ is described in this section.

\subsection{Retrieval of scaled cloud optical thickness}

We present here the methodology to retrieve scaled cloud optical thickness from Spinning Enhanced Visible and Infra Red Imager (SEVIRI) imagery. The relation between scaled cloud optical thickness $\left(\tau^{*}\right)$ and cloud optical thickness $(\tau)$ is explained below. SEVIRI is an imager with 11 spectral bands, extending from the shortwave to the thermal infrared portions of the electromagnetic spectrum. For our purposes, use is made of the spectral bands centred on $0.6 \mu \mathrm{m}$ and $1.6 \mu \mathrm{m}$. The $0.6 \mu \mathrm{m}$ channel is employed because of the negligible absorption by cloudy media at this wavelength, which considerably simplifies the expressions used for the retrieval. Reflectance in the $1.6 \mu \mathrm{m}$ channel is used to discriminate between the liquid and ice phases of cloud droplets, which are required in the SACURA method as implemented here.

The spatial resolution of the SEVIRI imagery is approximately $3 \mathrm{~km}$ at nadir. Yet, given the position of the MSG satellite platform (above the equator, and at $0^{\circ}$ longitude), the actual resolution over large part of Europe is approximately of the order of 4 to $6 \mathrm{~km}$. We acquired imagery for a geographical domain covering a large part of Europe, as shown in Fig. 1. This imagery was acquired for the month of June 2006, at time intervals of $15 \mathrm{~min}$, which is the temporal sampling provided by SEVIRI.

The shortwave reflectance was estimated from Level 1.5 SEVIRI imagery distributed by the European Organisation for the Exploitation of Meteorological Satellites (EUMETSAT). The spectral reflectance observed by the satellite is given as (Govaerts, 2001)

$R_{\lambda}=\frac{I_{\lambda} d_{\mathrm{SE}}^{2} \pi}{I_{\lambda 0} \cos \theta_{0}}$,

with $I_{\lambda}$ (in $\mathrm{Wm}^{-2} \mathrm{sr}^{-1}\left(\mathrm{~cm}^{-1}\right)^{-1}$ ) the radiance, which is obtained from the digital counts contained in the raw SEVIRI imagery, using appropriate offset and slope values for each spectral band. Furthermore, $d_{\mathrm{SE}}$ is the relative Sun-Earth distance, $I_{\lambda 0}$ is the spectrally dependent solar radiance at the 


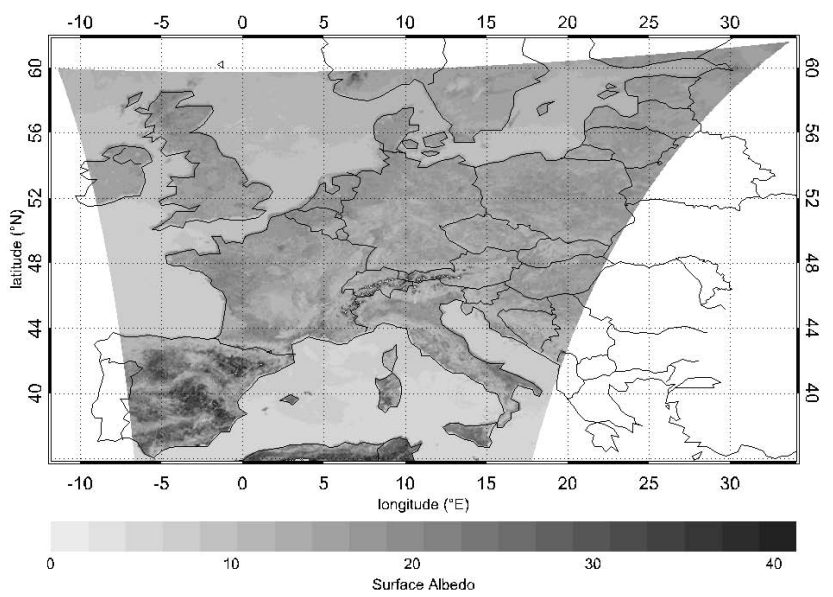

Fig. 1. Background surface albedo ( $A$ in \%) for June 2006 from minimum value compositing method. Region with high background surface albedo are shown in darker shade whereas lighter shade shows the region with low background surface albedo.

top of the atmosphere, and $\theta_{0}$ is the solar zenith angle. The description of calculation of $\theta_{0}$ is relegated to Appendix A. Note that, for the sake of clarity further in this study, the index $\lambda$ is dropped from the above expressions. It is assumed, though, that all spectrally-dependent quantities refer to the $0.6 \mu \mathrm{m}$ spectral band, which is the one used in SACURA for the retrieval of optical thickness.

Following Kokhanovsky et al. (2003), the reflection function of a cloud overlying a surface with albedo $A$ (the surface being assumed Lambertian) is given by

$R=R_{0}^{\infty}\left(\mu, \mu_{0}, \varphi\right)-t K_{0}(\mu) K_{0}\left(\mu_{0}\right)\left[1-\frac{A t}{1-A(1-t)}\right]$

where $R$ is the observed reflectance, $R_{0}^{\infty}\left(\mu, \mu_{0}, \varphi\right)$ is the reflectance of a semi-infinite cloud (see below), with $\mu=$ $\cos (\theta), \mu_{0}=\cos \left(\theta_{0}\right), \theta$ and $\theta_{0}$ being the satellite viewing and solar zenith angles, respectively, and $\phi$ the relative azimuth angle (see Appendix A) between the solar and satellite directions. Moreover,

$K_{0}(\mu)=\frac{3}{7}(1+2 \mu)$

is the escape function, and

$t=\frac{1}{0.75 \tau(1-\mathrm{g})+\alpha}$

is the global transmittance of a cloud, with $\tau$ the cloud optical thickness, $g$ the asymmetry parameter and $\alpha=1.07 \mathrm{a}$ numerical constant.

As mentioned above, $R_{0}^{\infty}\left(\mu, \mu_{0}, \varphi\right)$ is the reflectance of a semi-infinite cloud. In the earlier versions of SACURA, this quantity was parameterized in a simple manner. A drawback was that it was only valid for near-nadir viewing conditions, which for our study is problematic as viewing conditions of the SEVIRI instrument for Europe are generally fairly much off-nadir most of the time. Recently SACURA was extended (Nauss and Kokhanovsky, 2011) with an LUT approach for the estimation of this reflectance of a semi-infinite cloud, i.e. the first term in Eq. (2), thus allowing off-nadir viewing conditions, yet only marginally affecting the speed of the retrieval scheme. Moreover, the new LUT-based approach allows for both liquid and ice water phases.

LUT's for $R_{0}^{\infty}\left(\mu, \mu_{0}, \varphi\right)$ were acquired from http://www. iup.uni-bremen.de/ alexk/, one for water and another for ice clouds. (The method to discriminate between liquid and ice water clouds at a given pixel of the image is described below.) These LUTs contain pre-calculated values obtained by means of radiative transfer modelling (Nauss and Kokhanovsky, 2011), which are stored as a function of ( $\mu$, $\left.\mu_{0}, \phi\right)$, the latter increasing in steps of one degree. Values of $R_{0}^{\infty}\left(\mu, \mu_{0}, \varphi\right)$ are obtained by linear interpolation from the values stored in the LUT.

The actual retrieval of cloud optical thickness is now rather straightforward. Knowing $t$, Eq. (4) can be used to yield the cloud optical thickness $\tau$. However, rather than directly retrieving cloud optical thickness (COT) itself, we retrieve the scaled optical thickness (SCOT) instead, which (King, 1987) is defined as $\tau *=\tau(1-g)$, and which by virtue of Eq. (4) is given by

$\tau^{*}=\tau(1-g)=\frac{1}{0.75}\left(\frac{1}{t}-\alpha\right)$.

The main advantage of using SCOT is that it eliminates the effect of the asymmetry parameter $g$ on the result, which is important when intercomparing results obtained by different methods. This asymmetry parameter takes into account particle size, which depends on the phase of the cloud droplets. Zhang et al. (2009) showed the influence of different assumptions related to particle size, through its effect on $g$, in different retrieval algorithms. Particularly in the case of ice clouds, $g$ has a significant effect that can lead to errors of the retrieved parameters. By worthy with SCOT, uncertainties in the value of $g$, and hence in the retrieved parameter are avoided. The fact that the SCOT contains the 'hidden' information of $g$, is used later in this study, particularly for validation purposes.

The background (surface) albedo $A$ is an important quantity in the retrieval of SCOT as shown in Eq. (2), especially for thin cloud. Indeed, an improper specification of $A$ may bias the retrieved cloud optical thickness (King, 1987), particularly in the case of thin clouds. Here, $A$ is calculated from the imagery itself, using a minimum-value compositing approach, as was also done by Nauss et al. (2005). Stated otherwise, the background albedo map for our study domain is created by assigning to each pixel the minimum of the observed reflectance value over the entire study period. Figure 1 shows the map containing A obtained for June 2006, for our study domain. 
Finally, in our implementation to retrieve SCOT we employ a scheme to discriminate, at every pixel of a SEVIRI image, between the liquid and ice water phases of the cloud droplets. Ice versus water cloud discrimination is done using the ratio of the reflectances of the SEVIRI channels at $1.6 \mu \mathrm{m}$ and $0.6 \mu \mathrm{m}$, respectively (Kidder and Vonder Haar, 1995; Kokhanovsky, 2006). Based on the study by Hutchison (1999), whenever this ratio is below a value of 0.7 we assume ice clouds, the cloud containing liquid water otherwise. In each case, the corresponding ice or liquid water LUT is used to interpolate $R_{0}^{\infty}\left(\mu, \mu_{0}, \varphi\right)$ for ice and liquid water respectively.

\subsection{Estimation of surface UV irradiance}

In order to obtain reasonable surface UV irradiance from the remotely sensed COT fields, we developed a simple parameterization based on simulations performed with the Tropospheric Ultraviolet and Visible (TUV) radiative transfer model (Madronich, 1997), version 5.0. TUV is a state-ofthe-art model allowing to simulate, among others, the effect of clouds on surface UV irradiance.

As the objective here is to reproduce a reasonable level of surface UV irradiance incorporating the impact of remotely sensed cloud optical thickness, a value representative to the study period is assigned to the parameters of the TUV model. The TUV model is set up using the 8-stream discrete ordinates option. The surface albedo in the UV spectral range is set to $5 \%$, which is consistent with values mentioned by Badosa et al. (2005), Kazantzidis et al. (2001), López et al. (2009), and Palancar et al. (2011). The multi sensor re-analysis (MSR) data set created from fourteen total ozone satellite retrieval datasets measured by polar orbiting satellites (van der A et al., 2010) is used to obtain the total ozone column value. Following which, the total column ozone value is set to 335 Dobson Units for the month of June 2006 at $51^{\circ} \mathrm{N}$ and $4.5^{\circ} \mathrm{E}$, which is near the centre of our study domain. Note that the spatial variability throughout this domain is very little. The columnar concentration values for $\mathrm{SO}_{2}$ and $\mathrm{NO}_{2}$ are set to the TUV default values of $0 \mathrm{DU}$ and also for aerosol parameters default values are used: aerosol optical depth at $550 \mathrm{~nm}\left(\tau_{\mathrm{a}}=0.235\right)$, singlescattering albedo $\left(\omega_{0}=0.99\right)$, and Ångström coefficient as unity. The value of cloud asymmetry parameter $(g)$ employed to calculate $\tau$ from the remotely sensed scaled cloud optical thickness $\left(\tau^{*}\right)$ is set to 0.85 , which is consistent with the TUV model.

The TUV model is set up to calculate surface UV irradiance at sea level $(10 \mathrm{~m}$ altitude) for different cloud optical thickness values of $\tau=0,5,10,20,40$ and 80 , for solar zenith angles $\left(\theta_{0}\right)$ ranging from $0^{\circ}$ to $90^{\circ}$, in steps of $10^{\circ}$.

Inspired by Fitzpatrick et al. (2004), the function, $T(\tau)$, to calculate transmission of (broadband) solar radiation through clouds to modulate UV irradiance is given by:
$T(\tau)=\frac{a+b \cos \theta_{0}}{1+c \tau}$

A fit between TUV-based results and the above empirical function is obtained for $a=1, b=0.0$ and $c=0.075$. The correspondence between our parameterisation and the TUVbased results is excellent (Fig. 2).

The surface UV irradiance, $E\left(\tau, \theta_{0}\right)$, is expressed as the product of the clear-sky value $E\left(0, \theta_{0}\right)$ multiplied by the cloud transmissivity $T(\tau)$ as given in Eq. (6), yielding

$E\left(\tau, \theta_{0}\right)=E\left(0, \theta_{0}\right) T(\tau)$

As the solar zenith angle is one of the most important parameter affecting the surface UV levels (Lubin and Jensen, 1995), the clear-sky irradiance is parameterized as a function of solar zenith angle employing the functional form proposed by Simpson et al. (2002), that is,

$E\left(0, \theta_{0}\right)=E_{\tau=0} \exp \left[\gamma\left(1-\frac{1}{\cos \left(0.8 \theta_{0}\right)}\right)\right]$

The coefficient $\gamma$ is estimated, based on TUV results, to be 1.95 and 3.55 for UV-A and UV-B irradiance respectively.

The parameterization given by Eq. (7) is applied to time series of remotely sensed COT values for selected SEVIRI pixels, considering the same 15-min time intervals as those at which the cloud optical thickness is retrieved. In order to avoid the scattering phenomenon associated with lower solar elevation at the horizon and uncertainties in UV irradiance associated with it, the computation of surface UV irradiance levels is limited to the pixels having solar zenith angle $\left(\theta_{0}\right)$ smaller than $77^{\circ}$.

\section{Results}

\subsection{Comparison of optical thickness with CloudSat}

The methodology described in Sect. 2.1 was implemented on SEVIRI Level 1.5 daytime imagery to yield SCOT fields at 15-min intervals, for the month of June 2006. Figure 3 shows such fields at several selected instants corresponding to passes of the CloudSat instrument (Stephens et al., 2002), observations of which will be used to compare our results with.

CloudSat carries a 94-GHz cloud profiling radar, which yields cloud profile information, liquid and ice water content profiles, and precipitation. Optical thickness is obtained by combining radar measurements with reflectances measured by the MODIS instrument onboard the Aqua platform, which flies in tandem with the CloudSat platform. As the CloudSat radar has a small field of view of approximately $1.4 \mathrm{~km}$, and the platform being in a polar orbit, the data are confined to narrow tracks. Pixels within the tracks have a size of approximately $1.4 \mathrm{~km} \times 2.5 \mathrm{~km}$, in the across- and along-track directions, respectively. For the comparison, we used the CloudSat 

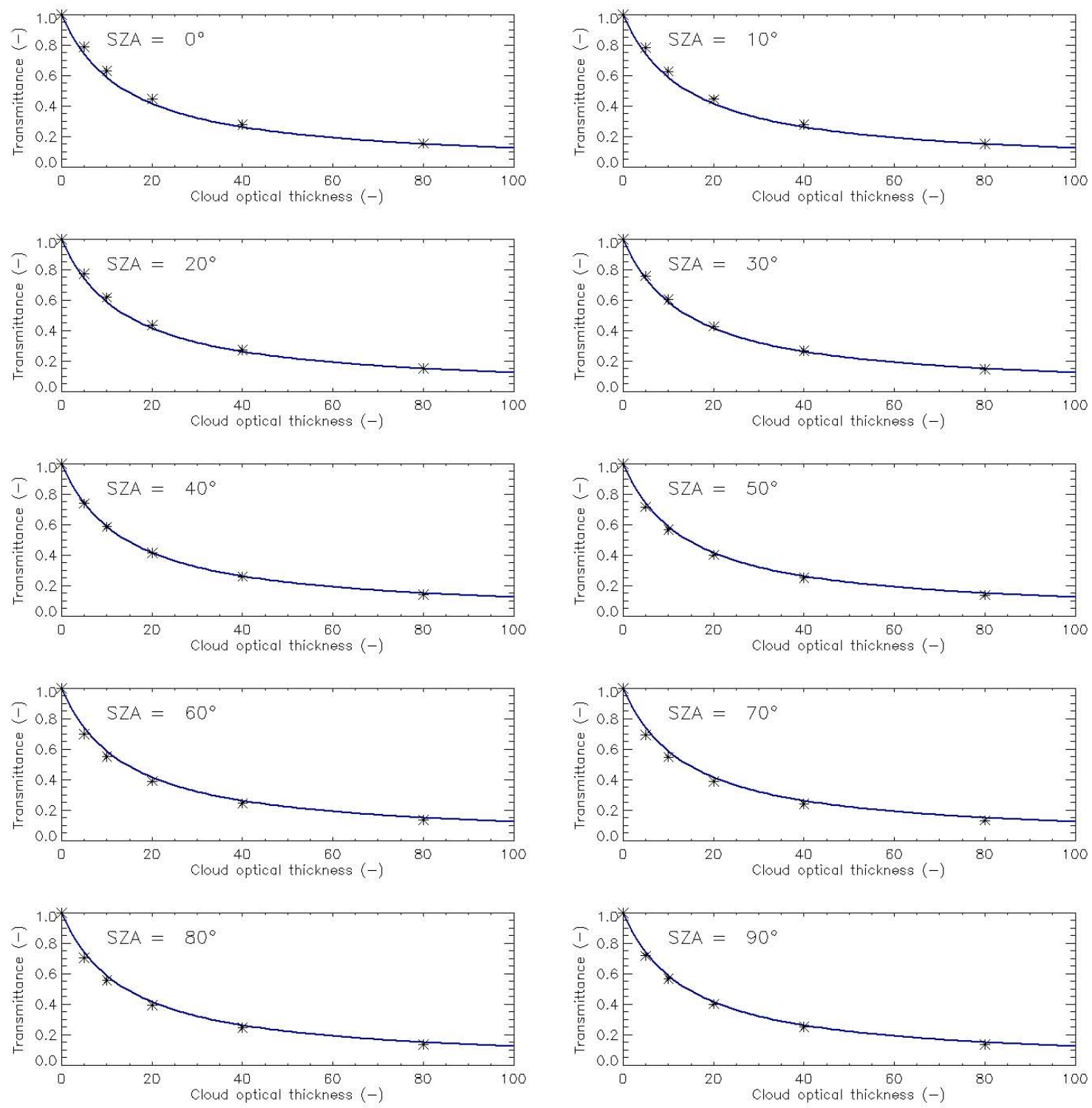

Fig. 2. The parameterised transmittance given by Eq. (6) (continuous curve) and the transmittance computed from TUV model simulations (symbols).

2B-TAU cloud optical thickness product (CloudSat Project, 2008). However, since we derived SCOT, while the CloudSat 2B-TAU product contains (unscaled) COT, we converted the latter to SCOT by using an appropriate value of the asymmetry parameter $g$. In the generation of the 2B-TAU product, use is made of a value of $g=0.85$ for water and $g=0.8336$ for ice droplets (Baum et al., 2005). As these values are very near each other, we adopted $g=0.84$ as a representative value for both the ice and liquid water phases.

SEVIRI-based SCOT results were interpolated to the positions of the CloudSat pixels along the tracks crossing our study domain (see Fig. 3). Figure 4 shows the result of the comparison between the SCOT values from SEVIRI versus those from CloudSat, along the track of the latter, for those times in June 2006 that a CloudSat track ran through the study domain, hence corresponding to the images in Fig. 3. It is quite clear that the SEVIRI results match the CloudSat SCOT values rather well, most of the time being within the uncertainty range of the latter. Whenever extensive and thick clouds are present in the CloudSat data, our SEVIRI-based SCOT values properly identify those areas. Also, the absence of cloud is identified well by our approach, although a small residual SCOT value is sometimes found in our results when CloudSat indicates the absence of cloud.

Table 1 quantifies the difference between the SEVIRI and CloudSat SCOT values for each of the CloudSat tracks used. The bias, ranging between -0.28 to 0.26 , is very low, without any general tendency towards systematically positive or 

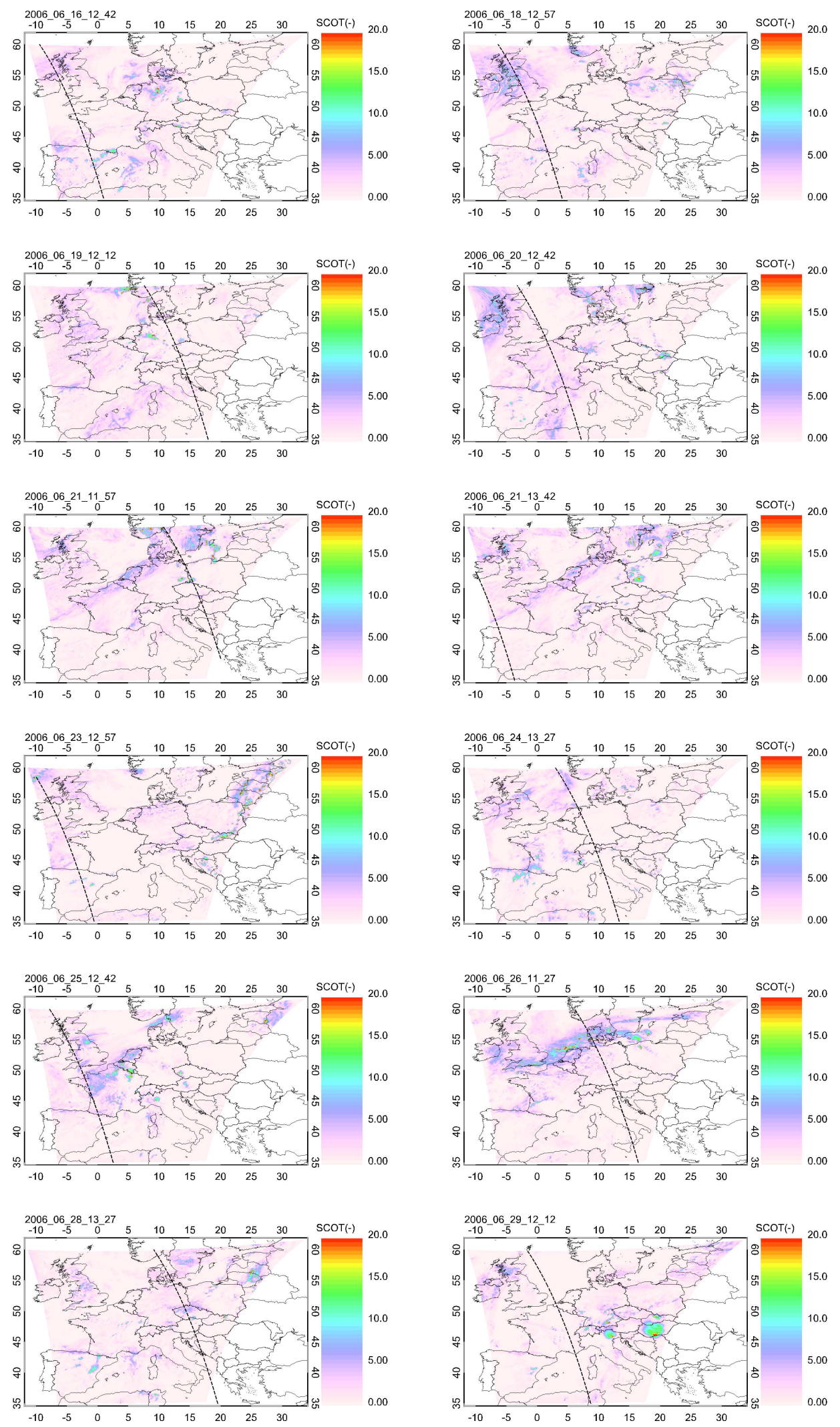

Fig. 3. SCOT fields at several selected instants, shown on top left of each map, corresponding to passes of the CloudSat instrument. The CloudSat passes are denoted by the dashed line. 

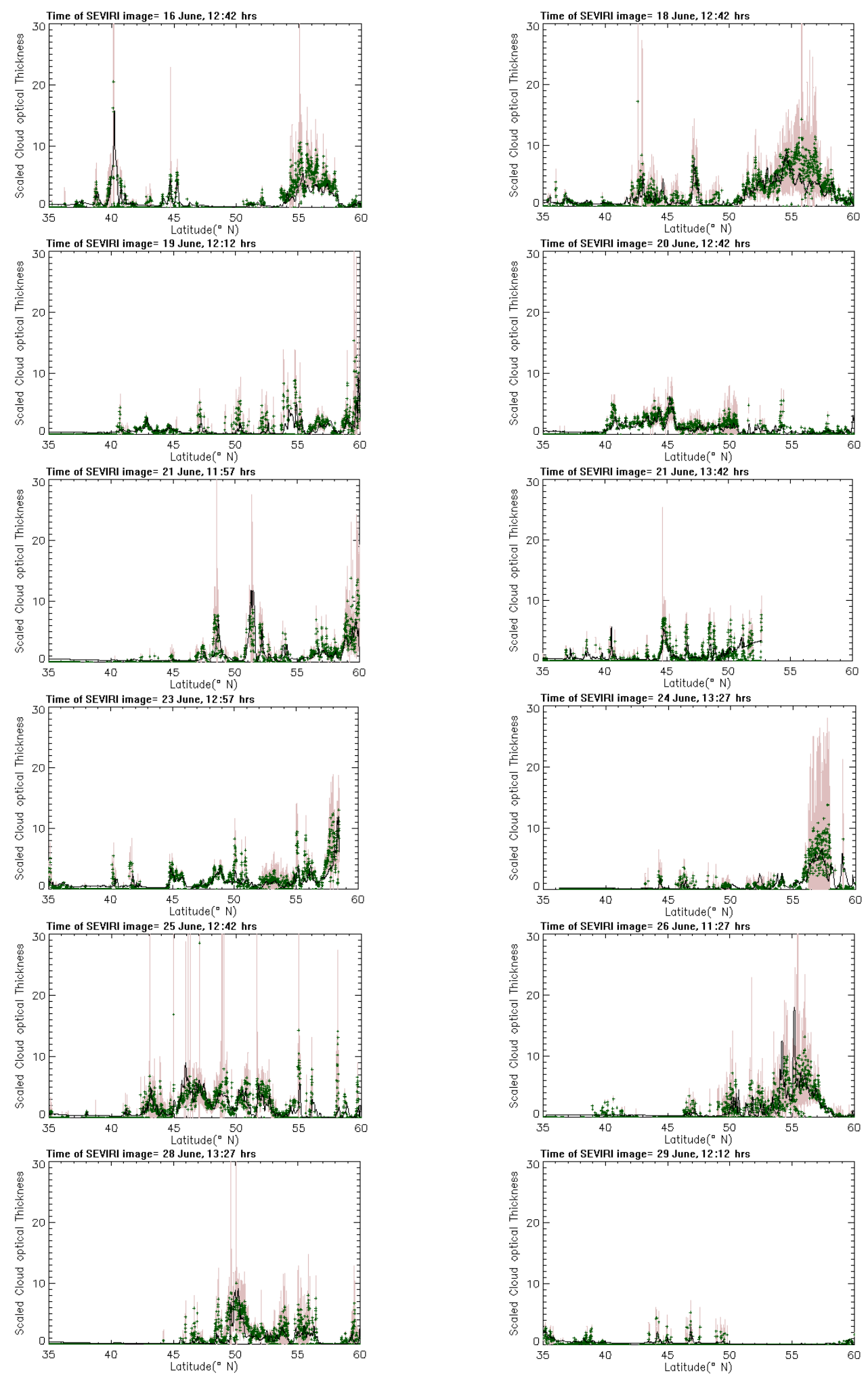

Fig. 4. Scaled cloud optical thickness $\left(\tau^{*}\right)$ retrieved from our approach (continuous black curve) and from CloudSat (green symbols). The uncertainity in the CloudSat values are given by the shaded region. 
Table 1. Error Statistics between estimated SCOT from SEVIRI and SCOT from CloudSat.

\begin{tabular}{lrrrr}
\hline $\begin{array}{l}\text { Time of CloudSat } \\
\text { pass over study domain }\end{array}$ & $\begin{array}{r}\text { Root Mean Square } \\
\text { Difference (RMSD) }\end{array}$ & $\begin{array}{r}\text { Index of } \\
\text { Agreement (IOA) }\end{array}$ & $\begin{array}{r}\text { Correlation } \\
\text { Coefficient }\end{array}$ & BIAS \\
\hline 16 June, 12:42 h & 1.68 & 0.78 & 0.69 & -0.23 \\
18 June, 12.42 h & 1.67 & 0.84 & 0.77 & -0.28 \\
19 June, 12:12 h & 1.22 & 0.72 & 0.59 & 0.04 \\
20 June, 12:42 h & 0.81 & 0.86 & 0.78 & 0.04 \\
21 June, 11:57 h & 1.65 & 0.80 & 0.67 & 0.03 \\
21 June, 13:42 h & 1.24 & 0.72 & 0.57 & 0.26 \\
23 June, 12:57 h & 1.40 & 0.80 & 0.72 & -0.09 \\
24 June, 13:27 h & 1.26 & 0.85 & 0.78 & 0.07 \\
25 June, 12:42 h & 2.12 & 0.68 & 0.58 & -0.05 \\
26 June, 11:27 h & 2.59 & 0.68 & 0.51 & 0.09 \\
28 June, 13:27 h & 1.36 & 0.78 & 0.63 & -0.10 \\
29 June, 12:12 h & 0.41 & 0.69 & 0.56 & 0.18 \\
\hline Mean & 1.45 & 0.77 & 0.65 & 0.00 \\
\hline
\end{tabular}

negative values. The root mean square difference (RMSD) is generally of the order of 1 to 2, which is rather low compared to the typical SCOT values occurring in the CloudSat tracks considered here, reaching up to values of $\sim 10$ and beyond. The correlation between both sets of SCOT values is also reasonably good, in the range $0.51-0.78$. Finally, the index of agreement also exhibits satisfactory values ranging between 0.68 and 0.86 , which points to a good performance of the retrieval scheme.

The SCOT values obtained from SACURA applied to SEVIRI are well within the uncertainty of the CloudSat values. The reason behind the differences in the SCOT can be attributed to differences in the spatial resolution between the SEVIRI and CloudSat pixels. A differing surface background albedo can also be associated with the discrepancies found in the SCOT.

In order to assess the agreement between results based on our approach against the CloudSat values, as expressed with the error statistics given above, we considered the results described in Kokhanovsky et al. (2007). These authors compared COT results obtained with SACURA applied to SCIAMACHY measurements, against results obtained based on MERIS and AATSR, also processed with the SACURA algorithm. The data obtained by these authors show correlation coefficients of 0.76 and 0.78 , and index of agreement (IOA) of 0.81 and 0.82, for MERIS and AATSR respectively. As mentioned above, we obtained a mean correlation of 0.65 and mean IOA of 0.77 in the comparison of our results with CloudSat. Any lesser performance of our approach may be explained by Eq. (1) different algorithms used for SEVIRI and CloudSat (whereas Kokhanovsky et al. (2007) used SACURA to measurements from both the MERIS and AATSR sensors), and Eq. (2) the mismatch between the pixels in the CloudSat track and the SEVIRI pixels, which is more severe than the spatial mismatch of SCIAMACHY versus spatially aggregated MERIS respectively AATSR data.
The difference statistics we obtained for the results based on our approach versus the CloudSat are reasonably satisfactory. This leads us to conclude that the application of SACURA algorithm to SEVIRI data yields satisfactory values for the scaled cloud optical thickness.

\subsection{Comparison of surface UV irradiance with measurements}

The resulting surface UV irradiance estimates computed by Eq. (7) were compared to measured values, obtained from UV monitoring stations located at Redu $\left(50.00^{\circ} \mathrm{N}, 5.15^{\circ} \mathrm{E}\right)$ and Ostend $\left(51.23^{\circ} \mathrm{N}, 2.93^{\circ} \mathrm{E}\right)$, both in Belgium, for the month of June 2006. Both stations have a fairly pristine atmosphere, as one is in a rural location and the other is located at the Belgian coast, not experiencing pollution of an urban region. The location of Redu and Ostend can be seen from Fig. 5, which also shows the cloud optical thickness fields of each day at noon (11:57 UTC) of June 2006 as estimated from SEVIRI. In this figure, different types of clouds - thin clouds, stratiform clouds, scattered or broken clouds, thick to cumulonimbus clouds - are identifiable by means of cloud optical thickness over the two sites. The two stations, which are part of the European UV measurement network (http://uvdb.fmi.fi/uvdb/), are equipped with UVB-1 and UVA-1 Pyranometers from Yankee Environmental Systems, Incorporated. The UVA-1 Pyranometer measures the global solar UV-A irradiance. The instrument utilizes colored glass filters and a UV-A sensitive phosphor screen to block all of the Sun's visible light and convert the UV-A light into visible (green) light. A solid-state photodetector is employed in the instrument to measure the latter. The UVB1 Pyranometer measures the global solar UV-B irradiance and utilizes the same technique as that of UVA-1 Pyranometer. These instruments are regularly verified and recalibrated by means of National Institute of Standards and Technology 

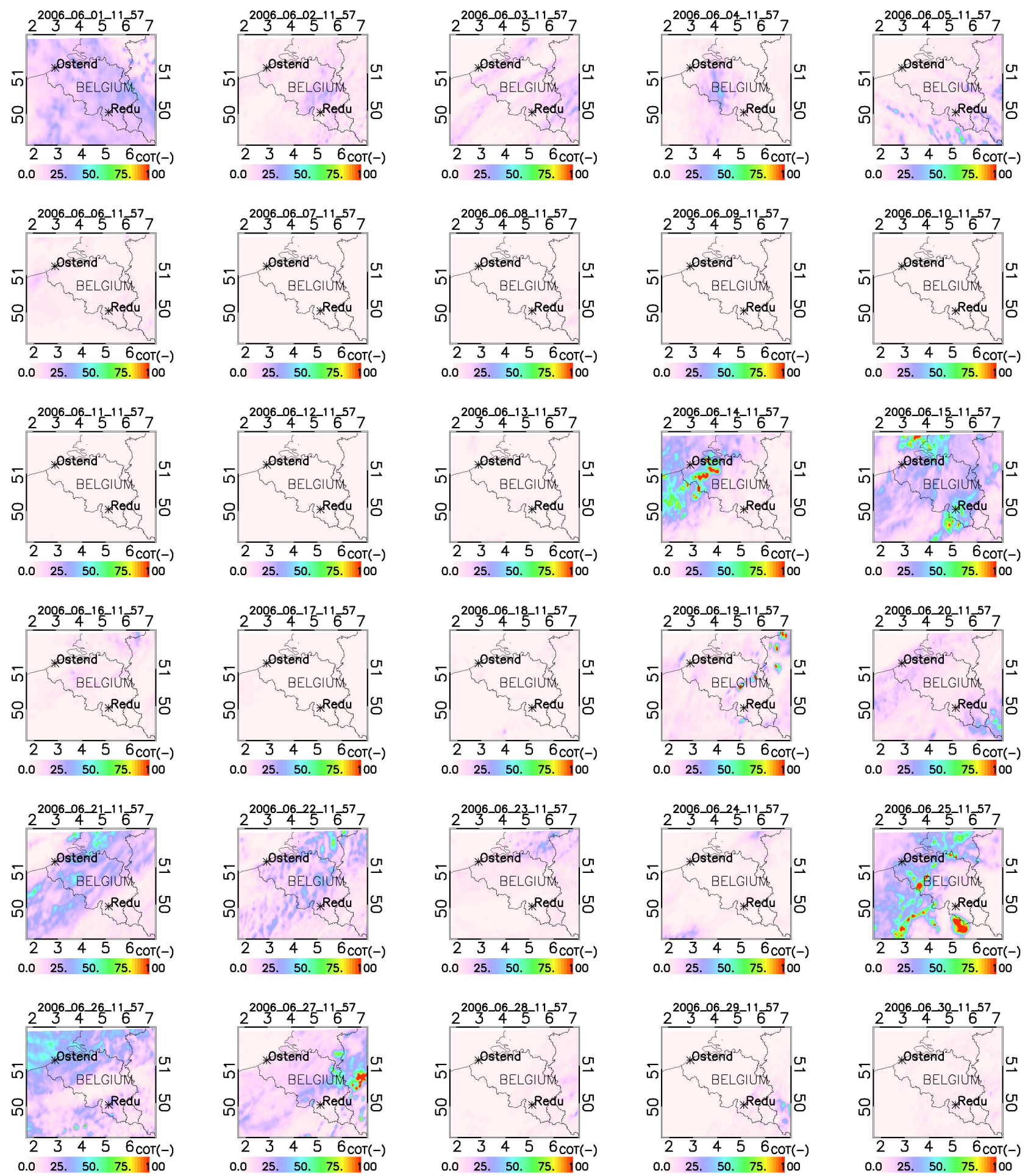

Fig. 5. Location of the measurement sites on a Belgian map with daily noon (11:57 UTC) cloud optical thickness values as retrieved from SEVIRI for the month of June 2006.

(NIST) certified $1000 \mathrm{~W}$ Tungsten lamps. One measurement is taken every second by both the UV-meters. The data are recorded on a data-logger and averaged on 1-min intervals between 2 to $22 \mathrm{~h}$ UT ( 4 to $24 \mathrm{~h}$ local time) each day. The accuracy of the UV irradiance measurements is estimated at $\pm 5 \%$.

Figure 6 shows the estimated versus the observed surface UV-A and UV-B irradiance values for June 2006 at the 

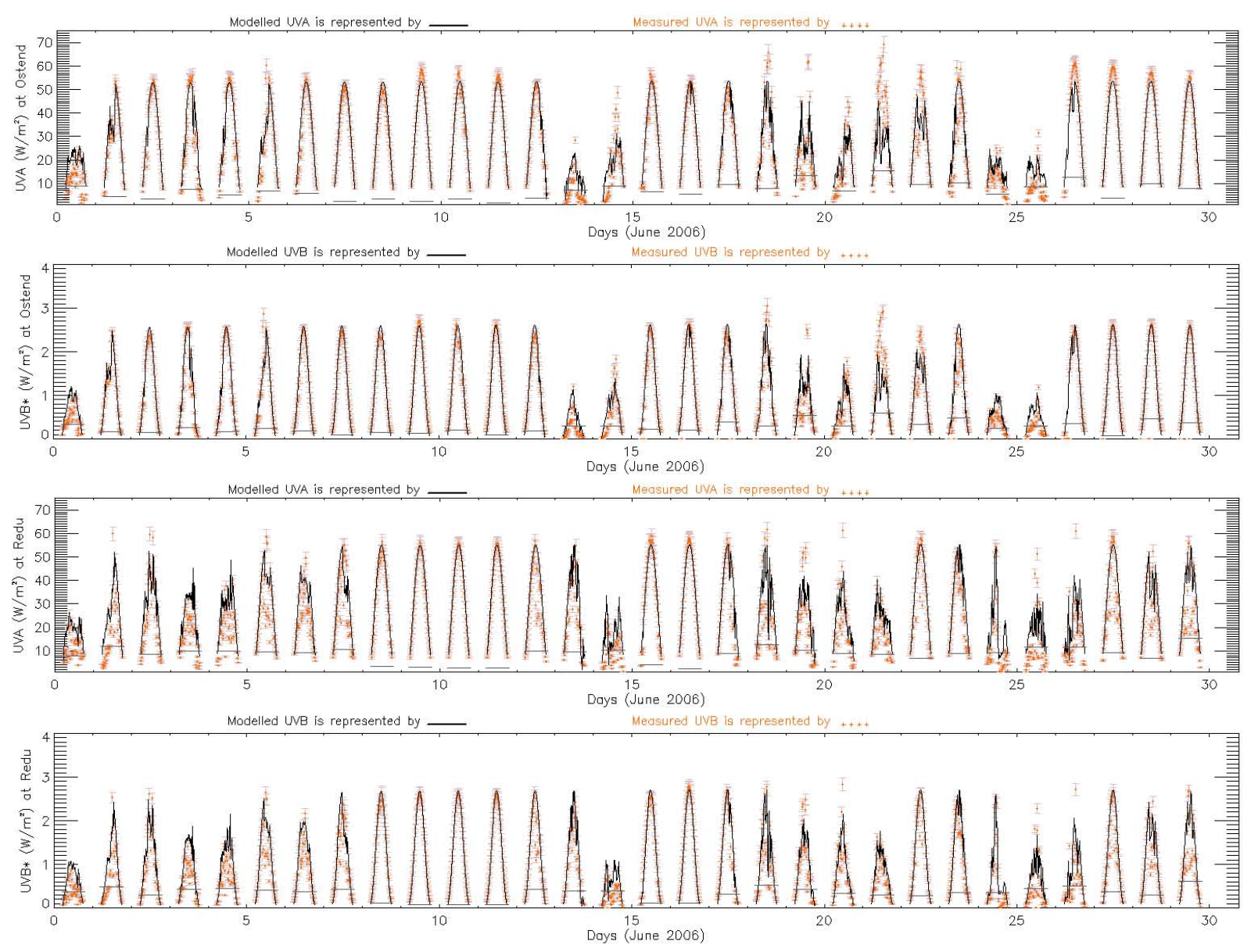

Fig. 6. Time series of modelled (solid lines) and measured (orange symbols) UV-A (a) and UV-B (b) irradiance over Ostend and UV-A (c) and UV-B (d) irradiance over Redu for the month of June 2006.

selected stations. It is clear that the estimated values capture the temporal variation of the observations fairly well. In particular, the variations between the obviously cloudy days versus the dominantly clear-sky periods are reproduced well in the COT-based surface UV estimates. Moreover, the geographic differences between the stations are generally well captured, such as the systematically lower irradiances in the Redu station at the beginning and the end of the considered period, and related to the presence of enhanced cloud at that location. There are also days, though, mostly characterized by (nearly) clear sky conditions, on which the model exhibits a low bias compared to the measurements. It has been reported that broken cloud decks or thin overcast cloud can enhance surface UV irradiance by up to several tens of percent, owing to light reflection at cloud edges and increased forward scattering in certain cloud types (Calbó et al., 2005; Crawford et al., 2003). The enhancement observed in the measurements might be due to the diffuse component of the UV radiation under the presence of very thin clouds. Another aspect to be kept in mind here as an explanation for some of the discrepancies is that the footprints (radiation source area) of the ground- versus the satellite-based sensors are different; moreover, for the ground-based sensor this footprint depends on the height of the cloud. Nevertheless, most of the time the estimated UV irradiances match the observations well, often within the $5 \%$ measurement error. Overall, the correspondence is slightly better for the UV-B than for the UV-A part of the spectrum.

The model versus measurement error statistics are shown in the Table 2. With the values of correlation varying from 0.88 to 0.91 for UV-A and UV-B, respectively, along with index of agreement ranging between 0.91-0.97, it can be inferred that the proposed parameterisation is a good estimate of attenuation of UV-A and UV-B irradiance due to clouds. The RMSE values of the time series for Ostend and Redu for UV-A are $7.7 \mathrm{~W} \mathrm{~m}^{-2}$ and $9.07 \mathrm{~W} \mathrm{~m}^{-2}$, respectively, whereas, for UV-B it is $0.30 \mathrm{~W} \mathrm{~m}^{-2}$ and $0.36 \mathrm{~W} \mathrm{~m}^{-2}$, respectively. The variation of daily RMSE, shown by the horizontal line in Fig. 6 indicates that the model and measurement values match well under clear sky condition. The influence of cloudy scenario, specially broken or transient clouds, 
Table 2. Error Statistics between estimated surface level UV irradiance and measurements.

\begin{tabular}{llrrrr}
\hline QUANTITY & STATION & $\begin{array}{r}\text { Root Mean } \\
\text { Square Error (RMSE) }\end{array}$ & $\begin{array}{r}\text { Index of } \\
\text { Agreement (IOA) }\end{array}$ & $\begin{array}{r}\text { Correlation } \\
\text { Coefficient }\end{array}$ & BIAS \\
\hline \multirow{2}{*}{ UVA } & Ostend & 7.70 & 0.94 & 0.91 & 2.15 \\
& Redu & 9.07 & 0.91 & 0.88 & 5.32 \\
\hline \multirow{2}{*}{ UVB } & Ostend & 0.30 & 0.97 & 0.93 & 0.05 \\
& Redu & 0.36 & 0.94 & 0.91 & 0.15 \\
\hline
\end{tabular}

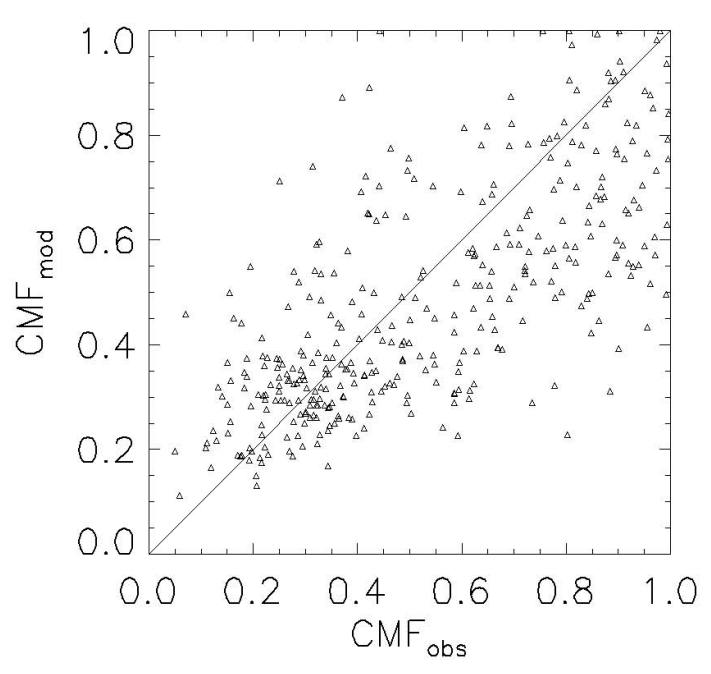

Fig. 7. A scatter diagram of modelled cloud modification factor $\left(\mathrm{CMF}_{\text {mod }}\right)$ versus observed cloud modification factor $\left(\mathrm{CMF}_{\mathrm{obs}}\right)$ over Ostend during June 2006.

somewhat deteriorates model performance for surface UV irradiance levels.

In addition to the above analysis, the conjunction of Fig. 6 and Fig. 5 also facilitates to comprehend the effect of clouds or absence of clouds on lower or higher surface UV irradiance levels respectively.

Figure 7 shows the comparison of modelled cloud modification factor (CMF) against the observed CMF over Ostend. The CMF was calculated as the ratio of observed UV irradiance to the clear sky UV irradiance. Despite the scatter (Fig. 7), the modelled and observed CMF match in a satisfactory manner with a root mean square error of 0.19 and a correlation coefficient of 0.71 . The bias has a value of 0.046 .

Although we do not propose a retrieval algorithm of surface UV irradiance from a remote sensing instrument, yet in order to assess the results obtained using our approach, we compared it with the results obtained by previous studies. We considered some of the previous studies that were dedicated to the estimation of surface UV irradiance using satellites. Chubarova et al. (2002) compared the ground based UV measurements at Moscow, Russia, against TOMS (Total Ozone Mapping Spectrometer), which has a spatial resolution of $50 \times 200 \mathrm{~km}^{2}$. They found that the relative mean difference between TOMS UV estimate and the ground measurements is between $\pm 10 \%$. They also found that TOMS overestimated the ground measurements under overcast condition as the value of the bias reached $15-17 \%$. Fioletov et al. (2002) found that the TOMS UV estimate versus ground measurements at Toronto, Canada, has a correlation coefficient of 0.9 with a bias of $9 \%$. McKenzie et al. (2001) found an average correlation of 0.81 between TOMS estimate and ground measurements of UV erythemal dose at four stations around the world. Peeters et al. (2000) compared the UVB estimated by GOME (Global Ozone Monitoring Experiment) against measurements over Uccle, Belgium. They found that the satellite estimations were twice as high as the measurements, particularly in the case of cloudy conditions. Among other factors, this difference pertains to the spatial resolution of GOME $\sim 40 \times 320 \mathrm{~km}^{2}$. Whereas, the results obtained using our approach yielded a mean correlation of 0.91 between modelled UV irradiance and ground based measurements with a low bias. The assessment of error statistics with that of previous studies reveal that the results obtained in this study matches satisfactorily with the results from previous studies. There are several reasons that limit an accurate intercomparison between our results with previous studies. Various studies employ various instruments/approaches, which does not measure exactly the same quantities and are focused over different geographical domains. These factors complicate the intercomparison of our results with previous studies. Moreover, the difference in spatial resolution of various remote sensing instruments, SEVIRI $=3 \times 3 \mathrm{~km}^{2}$ at nadir, TOMS $=50 \times 200 \mathrm{~km}^{2}$ and GOME $\sim 40 \times 320 \mathrm{~km}^{2}$, possess additional complications for comparisons together with the fact of using different spectral bands.

Finally, the differences between the estimated and measured surface UV irradiance could also pertain to the assumption related to the value of aerosol optical thickness (AOT). In the manuscript use was made of an AOT value of 0.235 . In order to assess the sensitivity of surface UV irradiance on AOT, we considered aerosol optical thickness measured by the AERONET (AErosol RObotic NETwork) station at Ostend (Belgium), which is very near the UV observation station. For the month of June 2006, the mean measured AOT amounted to 0.25 , with a standard deviation of 0.15 . The effect of the variability of the AOT on the resulting surface UV (UVA and UVB) irradiance was evaluated 
Table 3. Mean normalised absolute difference (MNAD) for UVA and UVB irradiance under varying aerosol optical thickness (AOT) values.

\begin{tabular}{lrr}
\hline $\begin{array}{l}\text { Aerosol optical } \\
\text { thickness (AOT) }\end{array}$ & $\begin{array}{r}\text { MNAD for } \\
\text { UVA (\%) }\end{array}$ & $\begin{array}{r}\text { MNAD for } \\
\text { UVB (\%) }\end{array}$ \\
\hline 0.10 & 3.22 & 3.43 \\
0.25 & 0.0 & 0.57 \\
0.40 & 3.22 & 5.44 \\
\hline
\end{tabular}

by calculating this quantity using the mean AOT (0.25), as well as the mean AOT plus and minus one standard deviation (AOT values of 0.10 and 0.40 , respectively). Perturbing the AOT as just explained induces mean normalised absolute difference (MNAD), which was calculated as following:

$\operatorname{MNAD}(\%)=\overline{\left(\frac{\left.\mid \mathrm{UV}_{\text {modelled }_{i}}-\mathrm{UV}_{\text {perturbed }_{i} \mid}\right)}{\mathrm{UV}_{\text {modelled }_{i}}}\right)} \times 100$

where, MNAD is Mean Normalised Absolute Difference in percent, $\mathrm{UV}_{\text {modelled }_{i}}$ is modelled UV (UVA or UVB) irradiance at $i$-th time interval, $\mathrm{UV}_{\text {perturbed }_{i}}$ is UV (UVA or UVB) irradiance associated with different values of aerosol optical thickness.

Table 3 quantifies the MNAD for UVA and UVB under varying AOT. It can be seen that the differences are small with maximum value of MNAD being $5.44 \%$ for UVB irradiance indicating the low sensitivity of surface UV irradiance to AOT.

\section{Conclusions}

This paper presents an application of the semi-analytical cloud retrieval algorithm (SACURA), designed for retrieving scaled cloud optical thickness, to MSG SEVIRI Level 1.5 reflectance imagery in the $0.6 \mu \mathrm{m}$ channel and estimation of corresponding surface UV irradiance. To illustrate model performance, a case study during the month of June 2006, for a domain covering a large part of Europe was analysed. To our best knowledge, this is the first application of SACURA to imagery obtained from a geostationary satellite platform to retrieve scaled cloud optical thickness (SCOT). The background (surface) albedo was determined from the reflectance imagery itself, using a minimum-value compositing method. The discrimination between liquid and ice water was done by means of a threshold method using the ratio of the $1.6 \mu \mathrm{m}$ versus the $0.6 \mu \mathrm{m}$ reflectance values. The SCOT values obtained with SACURA from SEVIRI imagery were compared with values estimated by the CloudSat satellite. Overall, both methods gave very similar results, both in magnitude as in the spatial patterns, with an average root mean square difference of 1.45 , index of agreement of 0.77 , correlation coefficient of 0.65 and null bias.
Based on the retrieved cloud optical thickness values together with radiative transfer modelling approach, a simple parameterisation as a function of solar zenith angle and cloud optical thickness was proposed to yield the surface level UV$A$ and UV-B irradiance. The estimated surface level UV-A and UV-B irradiance were validated against measurements over two Belgian stations, Redu and Ostend, for the same period of June 2006. The correlation between measurements and model results were found to be in the range of 0.88 to 0.91. The index of agreement varied between 0.91-0.97. A low bias was found between measurements and model results. A satisfactory modelled versus measured surface UV, UV-A and UV-B, irradiance leads to the conclusion that the proposed approach is competent in estimating the surface UV irradiance by capturing the impact of clouds characterised by remotely sensed scaled cloud optical thickness fields. The assessment of obtained results with previous studies yielded a satisfactory outcome. Finally, the sensitivity of surface UV irradiance level during the study period was found to be small with respect to the aerosol optical thickness.

A good estimate of surface UV irradiance levels also indicates the accuracy of the retrieved scaled cloud optical thickness values, specially for air quality applications among others.

\section{Appendix A}

\section{Solar-satellite angles}

\section{A1 Solar zenith angle}

The solar zenith angle $\left(\theta_{0}\right)$ is given as following:

$\theta_{0}=\cos ^{-1}\left(\sin \phi \sin \delta+\cos \phi \cos \delta \cos H_{\mathrm{a}}\right)$

with $\phi$ the latitude of the considered pixel's position, and

$\delta=-23.45 \cos \frac{2 \pi(\mathrm{JD}+10)}{365}$

the solar declination angle, which depends on the Julian Day (JD). The hour angle is given by

$H_{\mathrm{a}}=15(l-12)$,

with the local (solar) apparent time given by

$l=$ time $+\Omega+X_{\text {time }}$.

In this last expression "time" refers to the UTC time (in hours), $\Omega$ is longitude (in degrees), and

$\mathrm{X}_{\text {time }}=9.87 \sin 2 \beta-7.53 \cos \beta-1.5 \sin \beta$

is the equation of time, with $\beta=2 \pi(\mathrm{JD}-81) / 365$. 


\section{A2 Solar-satellite azimuth angles}

The solar azimuth angle $\left(v_{0}\right)$ is given as (Kidder and Vonder Haar, 1995),

$\nu_{0}=\cos ^{-1}\left(\frac{\cos H_{\mathrm{a}} \cos \delta \sin \Phi-\sin \delta \cos \Phi}{\sin \theta_{0}}\right)$.

Assuming a spherical earth, the radius vector extending from the centre of the Earth to the considered pixel, $\boldsymbol{r}_{\mathrm{e}}$, is given as

$\boldsymbol{r}_{\mathrm{e}}=\left(\begin{array}{l}\boldsymbol{r}_{\mathrm{e}} \cos \Phi \cos \Omega \\ \boldsymbol{r}_{\mathrm{e}} \cos \Phi \sin \Omega \\ \boldsymbol{r}_{\mathrm{e}} \sin \Phi\end{array}\right)$.

Similarly, $\boldsymbol{r}_{\mathrm{s}}$, the radius vector of the satellite is given by

$\boldsymbol{r}_{\mathrm{s}}=\left(\begin{array}{l}d_{\mathrm{v}} \cos \Phi_{0} \cos \Omega_{0} \\ d_{\mathrm{v}} \cos \Phi_{0} \sin \Omega_{0} \\ d_{\mathrm{v}} \sin \Phi_{0}\end{array}\right)$

where $\Phi_{0}=0^{\circ}$, is sub satellite latitude.

The difference vector being defined by, $\boldsymbol{r}_{\mathrm{d}} \equiv \boldsymbol{r}_{\mathrm{s}}-\boldsymbol{r}_{\mathrm{e}}$, the satellite zenith angle $(\theta)$, as described by Kidder and Vonder Haar (1995), is given by

$\theta=\cos ^{-1}\left(\frac{\boldsymbol{r}_{\mathrm{s}} \cdot \boldsymbol{r}_{\mathrm{d}}}{\left|\boldsymbol{r}_{\mathrm{s}}\right|\left|\boldsymbol{r}_{\mathrm{d}}\right|}\right)$.

To calculate the satellite azimuth angle (v), we employ two vectors in the tangent plane at the observational point. Again following Kidder and Vonder Haar (1995), the first vector pointing north, $\boldsymbol{r}_{\mathrm{N}}$, is given as

$\boldsymbol{r}_{\mathrm{N}}=\left(\begin{array}{l}-\sin \Phi \cos \Omega \\ -\sin \Phi \sin \Omega \\ \cos \Phi\end{array}\right)$.

The second vector, $\boldsymbol{r}_{\mathrm{H}}$, is the horizontal projection of $\boldsymbol{r}_{\mathrm{d}}$, given by

$\boldsymbol{r}_{\mathrm{H}}=\boldsymbol{r}_{\mathrm{d}}-\boldsymbol{r}_{\mathrm{d}} \frac{\boldsymbol{r}_{\mathrm{e}}}{\left|\boldsymbol{r}_{\mathrm{e}}\right|} \cos \theta$

From Eqs. (A9) and (A10) we obtain the satellite azimuth angle

$v=\cos ^{-1}\left(\frac{\boldsymbol{r}_{\mathrm{N}} \cdot \boldsymbol{r}_{\mathrm{H}}}{\left|\boldsymbol{r}_{\mathrm{N}}\right|\left|\boldsymbol{r}_{\mathrm{H}}\right|}\right)$.

The next parameter calculated is the relative azimuth angle $(\phi)$

$\phi=\left(v-v_{0}\right)+\pi$

We assume that the relative azimuth angle is equal to $\pi$ when sun and satellite are in the same line and sun is shining from behind the satellite, as described by Capderou (2005).

\section{Appendix B}

Table B1. List of symbols.

\begin{tabular}{lll}
\hline Symbol & Description & Units \\
\hline$I_{\lambda}$ & Radiance & $\mathrm{Wm}^{-2} \mathrm{sr}^{-1}\left(\mathrm{~cm}^{-1}\right)^{-1}$ \\
$\Phi$ & Latitude & Degree \\
$\Omega$ & Longitude & Degree \\
$\tau$ & cloud optical depth & - \\
$\tau^{*}$ & scaled cloud optical depth & - \\
$g$ & asymmetry parameter & - \\
$\theta_{0}$ & solar zenith angle & Degrees \\
$\theta$ & satellite zenith angle & Degrees \\
$v_{0}$ & solar azimuth angle & Degrees \\
$v$ & satellite azimuth angle & Degrees \\
$\varphi$ & relative azimuth angle & Degrees \\
$\delta$ & solar declination angle & Degrees \\
$R_{0}^{\infty}$ & reflectance of semi-infinite cloud & - \\
$R$ & observed reflectance & - \\
$K(\mu)$ & escape function & - \\
$t$ & global transmittance & - \\
$T$ & Solar broadband transmittance & - \\
$E$ & Surface UV irradiance & $\mathrm{W} \mathrm{m}$ \\
\hline
\end{tabular}

Acknowledgements. We are grateful to Alexander Kokhanovsky, Institute of Environmental Physics, Bremen University, Bremen, Germany, for his valuable guidance and suggestions in carrying out this work. We are thankful to EUMETSAT for providing us SEVIRI data. We are also thankful to CloudSat community for providing the data and their description. We would like to thank Kevin Ruddick for making the Ostend AERONET data available. We acknowledge also the support by the Climate and air quality modeling for policy support (CLIMAQS) project together with Promote air quality services integrating observations development of basic localised information for Europe (PASODOBLE) projects.

Edited by: P. Monks

\section{References}

Alados-Arboledas, L., Alados, I., Foyo-Moreno, I., Olmo, F. J., and Alcántara, A.: The influence of clouds on surface UV erythemal irradiance, Atmos. Res., 66, 273-290, 2003.

Badosa, J., González, J., and Calbó, J.: Using a parameterization of a radiative transfer model to build high-resolution maps of typical clear-sky UV index in Catalonia, Spain, J. Appl. Meteorol., 44, 789-803, 2005.

Baum, B., Yang, P., Heymsfield, A., and Thomas, S.: Bulk Scattering Properties for the Remote Sensing of Ice Clouds. Part I: Microphysical Data and Models, J. Appl. Meteorol., 44, 18851895, 2005.

Calbó, J., Pagès, D., and González, J: Empirical studies of cloud effects on UV radiation: A review, Rev. Geophys., 43, RG2002, doi:10.1029/2004RG000155, 2005.

Capderou, M.: Satellites-orbits and missions, Springer, 2005. 
Chubarova, N. E., Yurova, A. Y., Krotkov, N. A., and Herman, J. R.: Comparisons between ground measurements of broadband ultraviolet (300 to $380 \mathrm{~nm}$ ) and total ozone mapping spectrometer ultraviolet estimates at Moscow from 1979 to 2000, Opt. Eng., 41, 2070-3081, 2002.

ClouSat project: CloudSat standard data products handbook, 2008. Crawford, J., Shetter, R., Lefer, B., Cantrell, C. , Junkermann, W., Madronich, S., and Calvert, J.: Cloud impacts on UV spectral actinic flux observed during the International Photolysis Frequency Measurement and Model Intercomparison (IPMMI), J. Geophys. Res., 108, 8545, doi:10.1029/2002JD002731, 2003.

Estupinan, J. G., Raman, S., Crescenti, G. H., Streicher, J. J., and Barnard, W. F.: Effects of clouds and haze on UV-B radiation, J. Geophys. Res., 101, 16807-16816, 1996.

EUMETSAT: MSG ground segment LRIT/HRIT mission specific implementation, EUM/MSG/SPE/057, Darmstadt, Germany, 2006.

Fitzpatrick, M. F, Brandt, R. E., and Warren, S. G: Transmission of solar radiation by clouds over snow and ice surfaces: A parameterization in terms of optical depth, solar zenith angle, and surface albedo, J. Climate, 17, 266-275, 2004.

Fioletov, V. E., Kerr, J. B., Wardle, D. I., Krotkov, N., and Herman, J. R.: Comparison of Brewer ultraviolet irradiance measurements with total ozone mapping spectrometer satellite retrievals, Opt. Eng., 41, 3051-3061, 2002.

Govaerts, Y. M., Arriaga, A., and Schmetz, J.: Operational vicarious calibration of the MSG/SEVIRI solar channels, Adv. Space Res., 28, 21-30, 2001.

Hutchison, K. D.: Application of AVHRR/3 Imagery for the Improved Detection of Thin Cirrus Clouds and Specification of Cloud-Top Phase, J. Atmos. Ocean. Tech., 16, 1885-1899, 1999.

Kazantzidis, A., Balis, D. S., Bais, A. F., Kazadis, S., Galani, E., and Kosmidis, E.: Comparison of model caloculations with spectral UV measurements during the SUSPEN campaign: The effects of aerosols, J. Atmos. Sci., 58, 1529-1539, 2001.

Kidder, S. Q. and Vonder Haar, T. H.: Satellite meteorology- an introduction, Academic Press, 1995.

King, M. D.: Details of scaled optical thickness of cloud from reflected solar radiation measurements, J. Atmos. Sci., 44, 17341751, 1987.

King, M. D., Kaufman, Y. J., Menzel, W. P., and Tanré, D.: Remote Sensing of Cloud, Aerosol, and Water Vapor Properties from the Moderate Resolution Imaging Spectrometer (MODIS), IEEE T. Geosci. Remote, 30, 2-27, 1992.

Kokhanovsky, A. A.: Cloud Optics, Springer, The Netherlands, 2006.

Kokhanovsky, A. A. and Nauss, T.: Satellite-based retrieval of ice cloud properties using a semianalytical algorithm, J. Geophys. Res., 110, D19206, doi:10.1029/2004JD005744, 2005.

Kokhanovsky, A. A., Rozanov, V. V., Zege, E. P., Bovesmann, H., and Burrows, J. P.: A semi analytical cloud retrieval algorithm usinfg backscattered radiation in 0.4-2.4 $\mu \mathrm{m}$ spectral region, J. Geophys. Res., 108, 4008, doi:10.1029/2001JD001543, 2003.

Kokhanovsky, A. A., Nauss, T., Schreier, M., Huene, W. V. H., and Burrows, J. P.: The intercomparison of cloud parameters derived using multiple satellite instruments, IEEE T. Geosci. Remote, 45, 195-200, 2007.

Kudish, A. I. and Evseev, E.: Statistical relationships between solar UVB and UVA radiation and global radiation measurements at two sites in Israel, Int. J. Climatol., 20, 759-770, 2000.

López, M. L., Palancar, G. G., and Toselli, B. M.: Effect of different types of clouds on surface UV-B and total solar irradiance at southern mid-latitudes: CMF determinations at Córdoba, Argentina, Atmos. Environ., 43, 3130-3136, 2009.

Lin, X., Randall, D. A., and Fowler, L.: Diurnal Variability of the Hydrologic Cycle and Radiative Fluxes:Comparisons between Observations and a GCM, J. Climate, 13, 4159-4179, 2000.

Lubin, D. and Jensen, E. H.: Effects of clouds and stratospheric ozone depletion on ultraviolet radiation trend, Nature, 377, 710713, 1995.

Madronich, S.: Photodissociation in the atmosphere actinic flux and the effects of ground reflections and clouds, J. Geophys. Res., 92, 9740-9752, 1987.

Madronich, S. and Flocke, S.: Theoretical estimation of biologically effective UV radiation at the Earth's surface, in: Solar Ultraviolet Radiation - Modeling, Measurements and Effects, edited by: Zerefos, C., NATO ASI Series Vol. I52, Springer-Verlag, Berlin, 1997.

Mateos, D., Sarra, A., Meloni, D., Biagio, C. D., and Sferlazzo, D. M.: Experimental determination of cloud influence on the spectral UV irradiance and implications for biological effects, J. Atmos. Solar-Terr. Phys., 73, 1739-1746, 2011.

McKenzie, R. L., Seckmeyer, G., Bais, A. F., Kerr, J. B., and Madronich, S.: Satellite retrievals of erythemal UV dose compared with ground-based measurements at northern and southern midlatitudes, J. Geophys. Res., 106, 24051-24062, doi:10.1029/2001JD000545, 2001.

Monks, P. S., Rickard, A. R., Hall, S. L., and Richards, N. A. D.: Attenuation of spectral actinic flux and photolysis frequencies at the surface through homogenous cloud fields, J. Geophys. Res., 109, D17206, doi:10.1029/2003JD004076, 2004.

Moreno, I. F., Alados, I., Olmo, F. J., and Arboledas, L. A.: The influence of cloudiness on UV global irradiance $(295-385 \mathrm{~nm})$, Agr. Forest Meteorol., 120, 101-111, 2003.

MSG Level 1.5 image data format description (August 2007), EUMETSAT, 2007.

Nakajima, T. and King, M. D.: Determination of optical thickness and effective radius of clouds from reflected solar radiation measurements Part I: Theory, J. Atmos. Sci., 47, 1878-1893, 1990.

Nauss, T. and Kokhanovsky, A. A.: Retrieval of warm cloud optical thickness using simple approximations, Remote Sens. Environ., 115, 1317-1325, 2011.

Nauss, T., Kokhanovsky, A. A, Nakajima, T. Y., Reudenbach, C., and Bendix, J.: The intercomparison of selected cloud retrieval algorithms, Atmos. Res., 78, 46-78, 2005.

Palancar, G. G., Shetter, R. E., Hall, S. R., Toselli, B. M., and Madronich, S.: Ultraviolet actinic flux in clear and cloudy atmospheres: model calculations and aircraft-based measurements, Atmos. Chem. Phys., 11, 5457-5469, doi:10.5194/acp-11-54572011, 2011.

Peeters, P., Muller, J-F., Simon, P. C., Gillotay, D., Celarier, E. A., and Herman J. R.: Monitoring surface UV-B irradiance from space using GOME; Comparisons with ground-based measurements, Adv. Space Res., 26, 1941-1947, 2000.

Roebeling, R. A., Feijt, A. J., and Stammes, P.: Cloud property retrievals for climate monitoring: Implications of differences between Spinning Enhanced Visible and Infrared Imager (SEVIRI) on METEOSAT-8 and Advanced Very High Resolution 
Radiometer (AVHRR) on NOAA-17, J. Geophys. Res., 111, D20210, doi:10.1029/2005JD006990, 2006.

Saburg, J. M. and Parisi, A .V.: Spectral dependency of cloud enhanced UV irradiance, Atmos. Res., 81, 206-214, 2006.

Seckmeyer, G., Erb, R., and Albold, A.: Transmittance of a cloud is wavelength-dependent in the UV-range, J. Geophys. Res., 23, 2753-2755, 1996.

Simpson, W. R., King, M. D., Beine, H. J., Honrath, R. E., and Peterson, M. C.: Atmospheric photolysis rate coefficients during the Polar Sunrise Experiment ALERT2000, Atmos. Environ., 36, 2471-2480, 2002.

Stephens, G. L., Vane, D. G., Boain, R. J., Mace, G. G., Sassen, K., Wang, Z., Illingworth, A. J., O'Connor, E. J., Rossow, W. B., Durden, S. L., Miller, S. D., Austin, R. T., Benedetti, A., Mitrescu, C., and the CloudSat Science Team: The CloudSat mission and the A-Train: A new dimension of space-based observations of clouds and precipitation, B. Am. Meteorol. Soc., 83, 1771-1790, 2002.
Vázquez, M. and Hanslmeier, A.: Ultraviolet Radiation in the Solar System, Springer, 2006.

van $\operatorname{der}$ A, R. J., Allaart, M. A. F., and Eskes, H. J.: Multi sensor reanalysis of total ozone, Atmos. Chem. Phys., 10, 11277-11294, doi:10.5194/acp-10-11277-2010, 2010.

Zhang, Z., Yang, P., Kattawar, G., Riedi, J., Labonnote, L. C., Baum, B. A., Platnick, S., and Huang, H.-L.: Influence of ice particle model on satellite ice cloud retrieval: lessons learned from MODIS and POLDER cloud product comparison, Atmos. Chem. Phys., 9, 7115-7129, doi:10.5194/acp-9-7115-2009, 2009. 